\title{
Die berekening van die stukrag van 'n vuurpylmotor
}

\author{
J.H. Knoetze \\ Departement Chemiese Ingenieurswese, Universiteit van Stellenbosch, Stellenbosch 7600 \\ Ontrang 22 Marr 1993: anvaar 7 Julie 1993
}

\section{UITTREKSEL}

Tradisioneel word die stukrag van 'n vuurpylmotor bereken deur eers die stukragkoëffisiënt te bereken en dit te vermenigvuldig met die produk van die keelarea en die druk. Die stukragkoëffisiënt word bereken met 'n standaardvergelyking wat aan die gasdinamika ontleen is. Die onderliggende aanname wat gemaak word, is dat die vloeier 'n ideale gas is wat nie reageer nie en dat die vloei deur die mondstuk isentropies verloop. Die stukragkoëffisiënt is 'n funksie van die verhouding van spesifieke warmtes, $\gamma$, die areaverhouding van die mondstuk en die motor-en omgewingsdrukke. Standaardmetodes bestaan om die verliese as gevolg van nie-ideale vloeitoestande te hereken. Moderne saamgestelde dryfmiddels se verbrandingsprodukte hevat egter 'n beduidende hoeveelheid gekondenseerde spesies (hoofsaaklik $A I_{2} O_{3}$ ), terwl die samestelling voortdurend verander soos wat die produkte deur die mondstuk beweeg. Gevolglik ontstaan onsekerheid oor watter waarde van $\gamma$ gebruik moet word en hoe die gekondenseerde spesies gehanteer moet word. Die aanname van ideale, niereagerende vloei deur die mondstuk kan egter uitgeskakel word deur die proses slegs as isentropies te beskou en die stukrag te bereken op grond van die samestelling en termodinamiese toestand van die verbrandingsprodukte in die motor en in die uitlaatvlak van die mondstuk. Die meeste termochemierekenaarprogramme wat in die vuurpylhedryf gebruik word, is in stat om hierdie tipe berekening te doen. Dit is dus moontlik om die resultate van 'n standaardtermochemieprogram direk te gebruik in 'n alternatiew'e metode om stukrag te bereken. Hiervoor is slegs die massavloeitempo deur die mondstuk (wat 'n funksie is van die druk, keelarea en effektiewe karakteristieke snelheid) nodig wat dan saam met die resultate van die termochemieprogram gebruik word om stukrag te bereken. Dieselfde verliesberekeningsprosedure wat vir die stukragkoëffisiëntmetode gebruik word, kan ook hier gebruik word. Die voordele van die alternatiewe metode van stukragberekening word geillustreer aan die hand van 'n vergelyking tussen die resultate van die twee metodes met 'n praktiese stukragkurive.

\section{ABSTRACT}

\section{The calculation of the thrust of a rocket motor}

Traditionally the thrust of a rocket motor is calculated by first calculating the thrust coefficient and then multiplying it by the product of the throat area and pressure. The thrust coefficient is calculated using a standard gas dynamics equation. This equation assumes that the combustion products are a single component, non-reacting ideal gas and that the flow through the nozzle is isentropic. The thrust coefficient is a function of the ratio of specific heats, $\gamma$, the area ratio of the nozzle and the motor and ambient pressures. Standard methods exist for calculating the losses due to deviations from the assumed flow. The combustion products of modern composite propellants contain a significant portion of condensed species (primarily $\left.\mathrm{Al}_{2} \mathrm{O}_{3}\right)$, while the composition of the combustion products changes continuously as the products move throught the nozzle. Some uncertainty therefore exists with regard to which value of $\gamma$ to use and how to handle the condensed species. The assumption of an ideal, non-reacting gas can be eliminated by assuming the process to be isentropic and to calculate the thrust by using the thermodynamic state and composition of the combustion products in the motor and nozzle exit. This can be achieved by using any of the standard thermochemistry programs available in the rocket industry. It is thus possible to use the results of a standard thermochemistry program directly' in an alternative method for calculating thrust. Using this method only the mass flow rate (which is a function of pressure, throat area and effective characteristic velocity) and the results from the thermochemistry program are needed to calculate the thrust. The advantages of the alternative method are illustrated by comparing the results of the two methods with a measured thrust curve.

\section{INLEIDING}

Die stukrag wat deur 'n vuurpylmotor gelewer word, is die beginpunt vir enige werkverrigtingsanalise en is as sulks dus die belangrikste interne ballistiese parameter vir interne ballistiese berekeninge. Aandrywing word verkry deur 'n krag op 'n liggaam aan te wend. In 'n vuurpylmotor word hierdie krag verkry deur verbrandingsprodukte teen 'n hoë snelheid by 'n mondstuk uit te werp en dit staan bekend as stukrag. Die vereiste stukragverloop bepaal in 'n groot mate die motorgeometrie. Dit lê beperkings op die bedryfsdruk, die motorkeelarea en stel vereistes aan die dryfmiddelgeometrie.
Omdat die versnelling ook 'n funksie is van die gelewerde stukrag het dit ook " $n$ besliste invloed op die struktuur, of meer dikwels lê die struktuur sekere beperkings op die stukrag. Dit alles beteken dat die motorontwerper die stukrag akkuraat moet kan bereken ten einde 'n sinvolle motorontwerp daar te kan stel.

Die stukrag is egter ook een van die parameters waaroor die grootste onsekerheid tydens interne ballistiese berekeninge bestaan, omdat die akkurate berekening daarvan afhanklik is van die berekende waardes van die druk en mondstukkeelarea. Erosiewe verbranding en 
mondstukerosie veroorsaak egter dat daar reeds 'n redelike onsekerheid bestaan oor die berekende druk en keelarea sodat enige onakkuraatheid in die stukragberekening op die ander onakkuraathede gesuperponeer word. Hierdie publikasie het ten doel om die tradisionele metodes vir die berekening van stukrag krities te evalueer en om 'n alternatief daar te stel wat akkurater stukragkurwes lewer. Dit kan gedoen word deur die stukrag te bereken deur die termodinamika van die reagerende vloeier ook in ag te neem, in teenstelling met die tradisionele metode wat slegs die gasdinamika in ag neem.

\section{NOMENKLATUUR}

$\mathrm{A}_{\mathrm{e}} \quad=$ mondstukuitlaatarea

$\mathrm{A}_{\mathrm{t}}=$ keelarea

$\mathrm{C}_{\mathrm{F}} \quad=$ stukragkoëffisiënt

c* $=$ karakteristieke snelheid

$\mathrm{D}_{\mathrm{t}} \quad=$ keeldeursnee

$\mathrm{F}=$ stukrag

g = swaartekragversnelling

$\mathrm{I}_{\mathrm{sp}} \quad=$ spesifieke impuls

$\mathrm{I}_{\mathrm{spl}} \quad=$ teoretiese spesifieke impuls

$\mathrm{I}_{\text {valk }}=$ vakuumspesifieke impuls

$\mathrm{m} \quad=$ massavloeitempo

$\mathrm{P}_{\mathrm{a}} \quad=$ omgewinsdruk

$\mathrm{P}_{\mathrm{c}} \quad=$ motordruk

$\mathrm{P}_{\mathrm{e}} \quad=$ druk in mondstukuitlaatvlak

$\mathrm{P}_{\mathrm{ot}}=$ stagnasiedruk in keel

$\mathrm{t}=$ tyd

$\mathrm{u}_{\mathrm{c}} \quad=$ uitlaatsnelheid

$\eta \quad=\quad$ stukrageffektiwiteit

$\gamma=$ verhouding van spesifieke warmtes

$\varepsilon=$ keelerosietempo

$\mathrm{E} \quad=$ mondstukareaverhouding

3. BEREKENING VAN STUKRAG VOLGENS DIE TRADISIONELE METODE

Die stukrag van 'n vuurpylmotor kan in die afwesigheid van verliese met die volgende vergelykings bereken word: $1,2,3,4$

$$
\begin{gathered}
F=C_{F} P_{o t} A_{t} \\
\text { met } C_{F}=C_{\text {Fopt }}+\frac{A_{e}}{A_{t}}\left[\frac{P_{e}}{P_{c}}-\frac{P_{a}}{P_{\text {ot }}}\right] \\
\text { waer } C_{\text {Fopt }}=\left[\frac{2 \gamma^{2}}{\gamma-1}\left[\frac{\gamma+1}{\gamma+(\gamma+1) /(\gamma-1)}\right]\right. \\
{\left[1-\frac{P_{e}(\gamma-1) / \gamma}{P_{c}}\right]}
\end{gathered}
$$

Die inherente aannames wat in hierdie vergelyking vir die stukragkoëffisiënt gemaak word, is soos volg: ${ }^{3}$
(1) isentrope, eendimensionele vloei deur die mondstuk;

(2) vloeier is 'n een komponent ideale gas met konstante soortlike warmte en dus $\gamma$;

(3) geen reaksies vind gedurende vloei deur die mondstuk plaas nie.

Hierdie metode het sy ontstaan in die gasdinamika waar gewoonlik met gasse by hoë temperatuur gewerk word wat grotendeels soos ideale gasse optree. Die vergelykings was steeds aanvaarbaar vir vuurpylverbrandingsprodukte toe die meeste vaste dryfmiddels van die dubbelbasistipe was waarvan die verbrandingsprodukte feitlik uitsluitlik gasse was. Moderne saamgestelde dryfmiddels bevat egter 16 tot $20 \%$ aluminium. wat beteken dat ongeveer 30 tot 40 massa \% van die verbrandingsprodukte uit gekondenseerde spesies bestaan. Die aanname van ' $n$ ideale, niereagerende enkelkomponentgas is dus nie meer toepaslik nie. Die bydrae wat tweefase-effekte tot die onakkuraathede in die berekeninge lewer, word wel in ag geneem deur die sogenaamde tweefaseverliese te bereken, maar die verliesberekeninge maak nie voorsiening vir die verandering in samestelling en dus die waarde van $\gamma$ soos wat in die mondstuk afbeweeg word nie. Omdat die gasse nie ideaal is nie, verander die soortlike warmte ook soos wat die statiese temperatuur afneem soos die gasse deur die mondstuk versnel.

Die probleem van veranderende $\gamma$ word in tabel 1 geillustreer waar getoon word hoe $\gamma$ verander soos wat daar in 'n mondstuk afbeweeg word. Die vraag ontstaan dus onmiddellik watter waarde van $\gamma$ gebruik moet word om die stukragkoëffisiënt te bereken. Daar bestaan nie eenstemmigheid onder interne ballistici hieroor nie en feitlik elke instansie het sy eie gebruik, alhoewel die meeste instansies die waarde in die keel as die meer korrekte aanvaar.

TABEL 1

\section{Waarde van spesifieke warmteverhouding}

Dryfmiddel: PBAN-saamgestelde dryfmiddel met Al.

$\begin{array}{lllll}\text { Parameter } & \text { Motorruim } & \text { Keel } & \text { Uitlaat }(\epsilon=5) & \text { Uitlaat }(\epsilon=11) \\ \text { Druk [MPa] } & 5,0 & 2,87 & 0,19 & 0,06 \\ y & 1,1472 & 1,1515 & 1,1787 & 1,1942\end{array}$

Ten einde die stukrag vir 'n werklike vuurpylmotor te bereken, is dit egter noodsaaklik om ook die sogenaamde stukragverliese in aanmerking te neem. Hierdie verliesberekeninge het ten doel om die meeste van die vereenvoudigde aannames wat in die berekening van die ideale verlieslose stukrag gemaak word op 'n semi-empiriese manier in berekening te bring.

\section{VERLIESBEREKENINGE}

Verskeie publikasies bestaan wat gebruik kan word om die verliese te bereken. Die bekendste hiervan is die sg. SPP-metode ("Solids Performance Program"), SPOC- 
metode ("Solid Propulsion Optimization Code"), ${ }^{5}$ Davis 6 en die werk van Landsbaum en medewerkers. ${ }^{7,8}$ Die meeste van hierdie metodes het egter ten doel om die spesifieke impulsverliese te bereken, maar omdat daar 'n direkte verband tussen stukrag en spesifieke impuls bestaan (sien afdeling 5), is die metodes ook gebruik om die stukrageffektiwiteit te bereken. Die verliese word gewoonlik as volg in aanmerking geneem deur vergelyking [1] te skryf as:

$$
F=\eta C_{F} P_{\text {ot }} A_{t}
$$

waar die effektiwiteit, $\eta$, geskryf word as: $:^{5}$

$$
\eta=\left[\frac{\eta_{2 \mathrm{~F}}}{100} \frac{\eta_{\mathrm{div}}}{100} \frac{\eta_{\mathrm{kin}}}{100} \frac{\eta_{\mathrm{sub}}}{100} \frac{\eta_{\mathrm{b} 1}}{100}\right]
$$

$$
\begin{aligned}
\text { waar } \eta_{2 \mathrm{~F}}= & 100-\% \text { verlies as gevolg van } 2 \text {-fasevloei } \\
\eta_{\mathrm{div}}= & 100-\% \text { verlies as gevolg van } \\
& \text { mondstukdivergensie } \\
\eta_{\text {kin }}= & 100-\% \text { verlies as gevolg van eindige } \\
& \text { reaksiesnelhede } \\
\eta_{\text {sub }}= & 100-\% \text { verlies as gevolg van } \\
& \text { versonke mondstuk } \\
\eta_{\mathrm{bl}}= & 100-\% \text { verlies as gevolg van die opbou } \\
& \text { van die grenslaag in die mondstuk }
\end{aligned}
$$

SPOC gee die gewildste vergelykings vir die berekening van al die verliesparameters, behalwe dié vir 'n versonke mondstuk waar die metode gegee in die SPP gewilder is. ' $n$ Volledige beskrywing van elk van hierdie verliesparameters sou 'n aparte referaat kon beslaan en word nie hier gegee nie.

\section{ALTERNATIEWE METODE VIR DIE BEREKE- NING VAN STUKRAG}

In die bespreking van die tradisionele metode vir die berekening van die stukrag van 'n vuurpylmotor is gewys op enkele van die effekte wat nie in die berekening van die stukragkoëffisiënt in aanmerking geneem is nie. Dit is dus verkieslik om die ideale stukrag te bereken met behulp van 'n metode wat voorsiening maak vir sekere van hierdie effekte.

Die korrekste manier om die stukrag te bereken, is om van die basiese lineêre momentumvergelyking gebruik te mak. Dit lewer :

$$
F=m u_{e}+\left(P_{e}-P_{a}\right) A_{e}
$$

Die spesifieke impuls van 'n dryfmiddel word gedefinieer as die stukrag per eenheidsmassavloeitempo of te wel

$$
I_{s p}=\frac{F}{m}=u_{e}+\frac{\left(P_{e}-P_{a}\right) A_{e}}{m}
$$

Die verlieslose stukrag kan dus bereken word as:

$$
F=\mathbf{m} I_{\text {spt }}
$$

waar $I_{s p t}$ die teoretiese spesifieke impuls verteenwoordig.

Standaardtermochemieprogramme soos die van Gordon en $\mathrm{McBride}^{9}$ bereken die teoretiese spesifieke impuls vir 2 gevalle, naamlik:

(1) wanneer die uitlaatdruk, $P_{c}$, gelyk is aan die omgewingsdruk $\mathrm{P}_{\mathrm{a}}$;

(2) wanneer aangeneem word dat die omgewingsdruk 0 is, d.w.s. sogenaamde $I_{\text {vak }}$.

Hierdie waardes word deur die termochemieprogram bereken met die volgende aannames vir die vloei deur die mondstuk:

(1) eendimensionele, isentrope vloei deur die mondstuk

(2) ideale gasse;

(3) geen temperatuur of snelheidsverskil tussen gas en gek ondenseerde spesies nie;

(4) homogene vermenging;

(5) gevriesde of ekwilibriumvloei

Dit is dus duidelik dat die aspekte van die stukragkoëffisiëntmetode wat nie in die verliesberekeninge voorkom nie en tot probleme in die stukragberekeninge aanleiding gee, naamlik konstante samestelling, slegs ideale gasse en konstante $\gamma$ wel in aanmerking geneem word in die termochemieprogram, en gevolglik is vergelyking [8] "n akkurater vergelyking om te gebruik in interne ballistiese berekeninge as vergelyking [1].

Ten einde vergelyking [8] te gebruik, is dit egter nodig

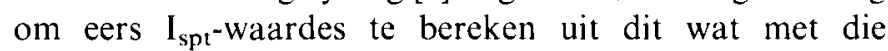
termochemieberekeninge verkry word. Gewoonlik is slegs die motordruk en die areaverhouding van die mondstuk bekend. Lopies word by verskillende drukke en verskeie areaverhoudings met die termochemieprogram uitgevoer. Toestande is selde sodanig dat die uitlaatdruk $\mathrm{P}_{\mathrm{e}}$ gelyk aan die omgewingsdruk is en as gevolg van mondstukerosie kan dit in elk geval nie oor die hele vuring die geval wees nie. Gevolglik moet die waardes soos gegee deur die termochemieprogram aangepas word. Dit kan soos volg geskied:

(1) Die spesifieke impuls $I_{\text {vak }}$ (gegee in sekondes) word as uitgangsparameter geneem.

(2) Bereken $I_{\text {spt }}$ as:

$$
I_{\text {spt }}=I_{\text {vak }}-\frac{P_{a} A_{e}}{m_{g}}
$$

(3) Vir termochemieberekeninge is $m$ egter nie bekend nie, wel die motordruk $P_{c}$ en mondstukareaverhouding, $A_{e} / A_{t}$. Die massavloeitempo deur die mondstuk word egter gegee deur: 


$$
m=\frac{P_{c} A_{t}}{c^{\star}}
$$

(4) Stel [10] in [9]:

$$
I_{s p t}=I_{v a k}-\frac{P_{a} A_{e} c^{\star}}{P_{c} A_{t} g}
$$

In vergelyking [11] is alle parameters nou beskikbaar sodat $I_{\mathrm{spt}}$ by ' $\mathrm{n}$ reeks motordrukke en areaverhoudings bereken kan word. Met $I_{\mathrm{spt}}$ bekend, kan vergelyking [8] nou gebruik word om die ideale stukrag te bereken.

Daar kan vir verliese voorsiening gemaak word deur vergelyking [8] te skryf as:

$$
F=\eta \mathrm{m} \mathrm{I}_{\text {spt }}
$$

Die verliesparameter $\eta$ word soos voorheen in afdeling 4 verduidelik, bereken.

\section{VERGELYKING TUSSEN METODES}

Die twee metodes vir die berekening van stukrag is vervolgens met mekaar vergelyk deur die drukkurwe van 'n spesifieke vastedryfmiddel-vuurpylmotorvuring te neem en die berekende stukragkurwes met mekaar te vergelyk. Vir die doeleindes van die vergelyking is aanvaar dat die motor se mondstukkeel lineêr ge-erodeer het en dat die tydafhanklike keeldeursnee gegee word deur:

$$
D_{t}=D_{t o}+\varepsilon t
$$

Alle berekende waardes is geskaleer, gevolglik word die stukrag en tyd slegs op 'n skaal tussen 0 en 1 aangedui en die totale impuls as \% aangegee. Vir die berekeninge volgens die stukragkoëffisiëntmetode is drie waardes van $\gamma$ ondersoek, naamlik die waarde in die motorruim, die waarde in die mondstukkeel en die waarde in die mondstukuitlaatvlak. Die resultate word in tabel 2 opgesom, terwyl figuur I die resultate van die berekeninge volgens die tradisionele metode toon. Figuur 2 toon hoe die gemete stukragkurwe vergelyk met die berekende stukragkurwes volgens die tradisionele metode (die beste kurwe van figuur 1 ) en die nuwe alternatiewe metode.

Tabel 2 toon dat die alternatiewe metode die totale impuls baie akkurater kan voorspel as die tradisionele metode en dus 'n groot verbetering teweegbring. Die tabel en figuur 1 toon ook dat selfs indien die drukkurwe met ' $n$ interne ballistiekprogram heeltemal akkuraat voorspel sou word daar nog 'n redelike fout in die voorspelde stukragkurwe kan voorkom. Tabel 2 en figuur 2 toon ook dat die alternatiewe metode nie addisionele onakkuraathede tot gevolg sou hê nie, op voorwaarde dat die drukkurwe akkuraat bekend is. Daar moet onthou word dat in hierdie geval die gemete drukkurwe as beginpunt geneem is, terwyl by 'n werklike simulasie die drukkurwe bereken sou moes word. Praktiese simulasieresultate sou dus oor die algemeen swakker wees, maar die alternatiewe metode vir die berekening van stukrag sal deurgaans akkurater resultate lewer. Die figure toon ook dat die ooreenstemming tussen die gemete en berekende kurwes swakker word soos wat die tyd verloop. Dit dui daarop dat die lineêre model vir keelerosie sekere gebreke toon en dat vergelyking [13] nie die tydafhanklike keeldeursnee heeltemal akkuraat weergee nie. Die alternatiewe metode is natuurlik meer sensitief vir onakkuraathede in die resultate van die termochemieprogramme as die tradisionele metode.

Die resultate van die berekeninge volgens die tradisionele metode toon ook dat akkurater resultate verkry word indien $;$ by die motorruimtoestande geneem word eerder as by die keel, alhoewel die keelwaarde meer dikwels gebruik word.

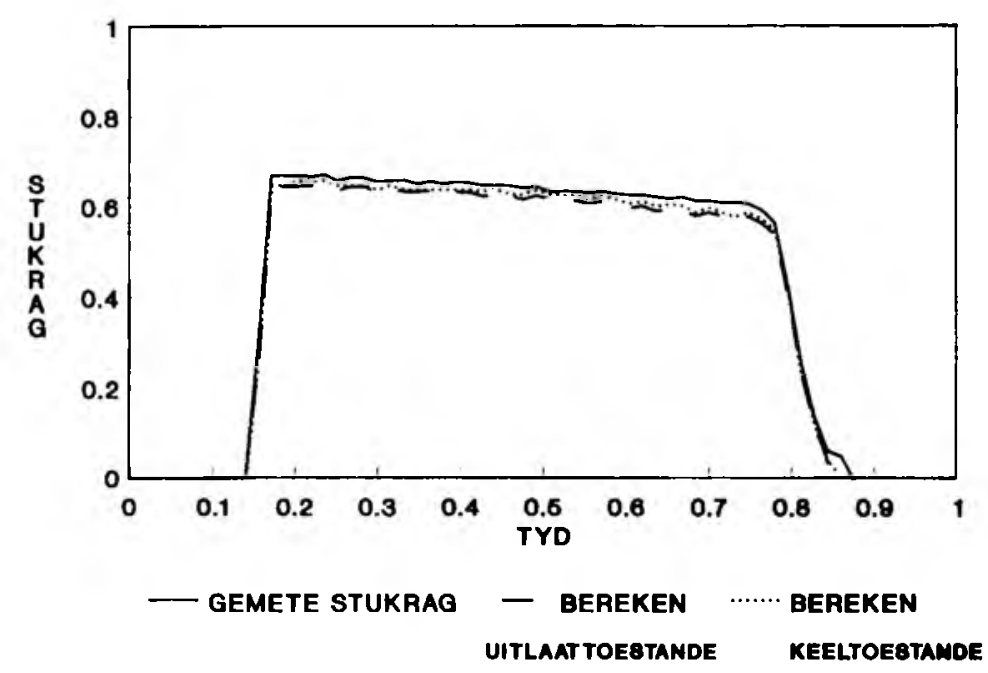

FIGUUR 1: Stukrag volgens konvensionele metode.

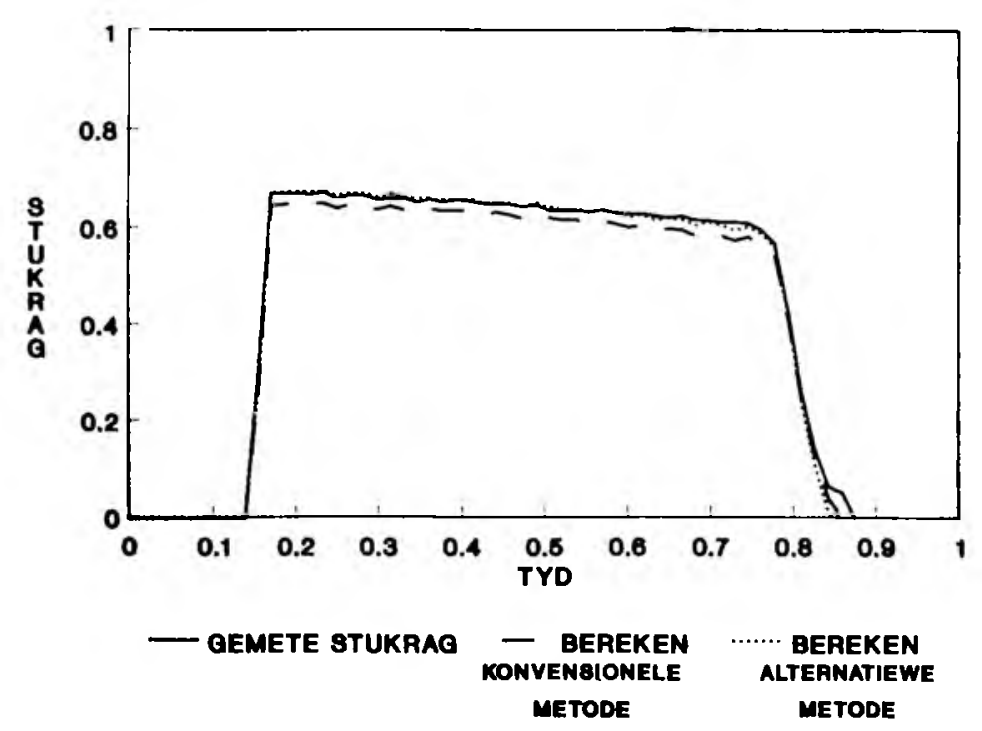

FIGUUR 2: Vergelyking tussen metodes. 
TABEL 2

Vergelyking van totale impuls volgens verskillende metodes bereken

\section{METODE}

Gemeet

Stukragkoëffisiënt:

$\gamma=1,1472$ (motorruim)

$\gamma=1,1515(\mathrm{keel})$

$\gamma=1,193$ (mondstukuitlaat)

Alternatiewe metode:

TOTALE IMPULS (\%) 100

98,9

98,7

96,9

99,9

\section{GEVOLGTREKKINGS}

Twee alternatiewe metodes vir die berekening van die stukrag van 'n vuurpylmotor is met mekaar vergelyk. Vergelyking met praktiese resultate het getoon dat die alternatiewe metode waar gebruik gemaak word van die teoretiese spesifieke impuls akkurater resultate gee as die tradisionele metode waar die stukragkoëffisiënt as funksie van die spesifieke warmteverhouding, $\gamma$, bereken moet word. Vir die stukragkoëffisiëntmetode word die akkuraatste waardes verkry indien die waarde van $\gamma$ by die motorruimtoestande gebruik word.

\section{LITERATUURVERWYSINGS}

I. Sutton, G.P. (1986). Rocket Propulsion Elements (5th ed.) (John Wiley \& Sons) pp. 49-50.

2. Timat, Y.M. (1987). Advanced Chemical Rocket Propulsion (Academic Press, London) pp. 3-4.

3. Williams, F.A., Barrere, M. \& Huang, N.C. (1969). Fundamenta] Aspects of Solid Propellant Rockets. AGARDograph 116 (Technivision, Slough, England) pp. 60-65.

4. Barrere, M., Jaumotte, A., De Veubeke, B.F. \& Vandenkerckhove, J. (1960). Rocket Propulsion (Elsevier, Amsterdam) pp. 88-90.

5. Roys, G.P. (1981). User's Manual for Solid Propulsion Optimization Code (SPOC) Vol 1: Technical Description. AFRPL-TR. 81-70.

6. Davis, D.K. (1985) Review of Empirical and Analytical Specific Impulse Methodologies. AIAA-85-1434 (American Institute for Aeronautics and Astronautics).

7. Landbaum, E.M., Salinas, M.P. \& Leary, J.P. (1970), Specific Impulse Prediction of Solid-Propellant Motors. J. Spacecraft, 17, 400-406.

8. Landbaum, E.M. \& Salinas, M.P. (1979). Solid Propellant Specific Impulse Prediction. AGARD Symposium on Solid Rocket Motor Technology (Oslo, Norway) pp. 5-1, 5-11.

9. Gordon, S. \& McBride, B.J. (1973). Computer Program for Calculation of Complex Chemical Equilibrium Compositions, Rocket Performance, Incident Shocks, and Chapman-Jouguet Detonations (NASA SP-273, NASA). 